\title{
Sodium Bicarbonate Treatment on Mechanical and Morphological Properties of Coir Fibres
}

\author{
B. Bakri 1,2 A. E. E. Putra ${ }^{2 *}$, A. A. Mochtar ${ }^{2}$, I. Renreng ${ }^{2}$ and H. Arsyad ${ }^{2}$ \\ ${ }^{1}$ Mechanical Engineering Department, Tadulako University, Palu Indonesia \\ ${ }^{2}$ Mechanical Engineering Department, Hasanuddin University, Gowa Indonesia \\ *Email: erwin_eka_putra@yahoo.com
}

Phone: +62411586015

\begin{abstract}
Natural fibres as reinforcement of composite have been applied during the last decade. One of natural fibre has been used as reinforcement is coir fibre. As reinforcement of composite, such fibre needs treatment to improve compatibility with its matrix with suitable treatment. In this paper, surface treatment of such fibre was conducted using sodium bicarbonate $\left(\mathrm{NaHCO}_{3}\right)$ solution with various densities and soaking time differences. Mechanical and morphological properties of coir fibre were investigated. Coir fibres were soaked in the $8 \mathrm{wt} \%, 10 \mathrm{wt} . \%$, and $12 \mathrm{wt} . \%$ sodium bicarbonate solution for 24 hours and 120 hours. After treatment, coir fibres were characterized with tensile testing, scanning electron microscope (SEM), Fourier transform infrared (FTIR) and x-ray diffraction (XRD). The results suggested that mechanical properties of coir fibre after sodium bicarbonate solution changed for all densities and soaking time. The coir fibre treated in $12 \mathrm{wt} . \%$ sodium bicarbonate for soaking time 120 hours has highest tensile strength. The surface morphology of fibre was analyzed by using SEM. It showed micropores on the fibre surface which may influence the mechanical properties of coir fibre.
\end{abstract}

Keywords: Coir fibre; sodium bicarbonate; mechanical properties; soaking time.

\section{INTRODUCTION}

Natural fibres have been used as reinforcement of composite. Such fibres have taken more attention due to their advantages such as specific strength, biodegradability, and low price and environmentally friendly [1-3]. However, its poor compatibility with matrix has been a drawback as reinforcement of composite because of hydrophilic natural fibres and hydrophobic matrix [4]. To solve this issue, surface modifications of natural fibres have been studied by some researchers. Chemical treatment is one of methods which has been used to improve this compatibility such as alkalization or mercerization, silane and benzene diazonium salt treatments of coir fibres improved the adhesion of fibre-matrix in the composite [4,5]. Alkali treatment of natural fibre has been conducted on henequen fibres [5], Napier grass fibres [6], coir fibres [7-11], Borassus fruit fine fibres [12], coconut sheath fibre [13], sisal and kapok [14]. Lignin and some impurities in the fibres can be removed by alkali treatment. In addition, cellulose structure depolymerization can occurred and crystallites of natural fibres were changed during the treatment [15]. Another chemical substance used to modify of the surface of natural fibres is sodium bicarbonate. This sodium bicarbonate treatment is an eco-friendly treatment due to its non-toxic properties. Fiore et al. [3] have investigated 
the effect of sodium bicarbonate treatment on mechanical properties of sisal fibres and its adhesion with epoxy matrix in the composite. The treated sisal fibres with $10 \% \mathrm{w} / \mathrm{w}$ of sodium bicarbonate for 120 hours has significantly improved tensile properties of fibres and has increased compatibility between sisal fibres and epoxy matrix. The sodium bicarbonate has been mixed with chromium sulfate solution for surface modification of ladies finger fibre [16], and coir fibre [17].

One of natural fibres which has been developed for reinforcement of composite is coir fibre. This fibre has low tensile and modulus strengths, but it has high elongation compared to other natural fibres [18,19]. Prasad et al. [20] investigated that alkali treatment with $5 \% \mathrm{NaOH}$ solution for 72 to 96 hours of coir fibres increased the tensile strength and improved wettability between coir fibre and polyester. Meanwhile the extended soaking time after 96 hours, the tensile strength of such fibres decreased due to removing the cuticle and the bonding material of the fibres. Furthermore, Nam et al. [9] evaluated that when the coir fibres were treated in $5 \% \mathrm{NaOH}$ solution for 72 hours, the tensile strength of such fibres was the higher than untreated and other treatments $(5$ $\% \mathrm{NaOH}$ for 24, 48 and 96 hours) of coir fibres. Beside the increase of the tensile properties of such fibres due to alkali treatment, the surface roughness of coir fibres also enhanced which may improve the mechanical interlocking of fibre-poly(butylene succinate) matrix in the composite so that it rised the mechanical properties of composite. In addition, $\mathrm{Gu}$ [21] studied the treated coir fibres with 2-10\% consentrations of alkali treatment as reinforcement of composite. Result showed that the tensile strength of coir fibre tended to decrease with the higher consentration of alkali treatment. This may be caused by removal of the components of coir fibre like lignin, cellulose, pectin and fatty acid which induces the damage of the fibre strength. Meanwhile, the tensile strength of treated coir fibre composite was higher than untreated coir fibre composite. It caused by the improvement of fibre-matrix adhesion due to leaching out of fatty, pectin and lignin which lead to surface roughness of the coir fibres so that it would be mechanical interlocking between fibre and matrix occur. Then, addition of compatibilizer to coir fibre-matrix composite improved bonding of fibre-matrix and raised tensile strength [22]. Eco-friendly treatment of coir fibre using plasma treatment was carried out by Praveen et al. [23] and de Farias et al. [24].

Based on research of Fiore et al. [3] and environmentally friendly consideration of coir fibre treatment, this paper presents the effect of different densities ( $8 \mathrm{wt} . \%, 10$ wt. $\%$ and $12 \mathrm{wt} . \%$ ) of sodium bicarbonate solution with soaking time (24 hours and 120 hours) on mechanical and morphological properties of coir fibres. The effect of sodium bicarbonate solution on coir fibres can be determined by mechanical testing for mechanical properties and SEM characterisation for surface morphology. FTIR spectrum was conducted to analyze chemical composition, while XRD analysis to measure crystallinity indices.

\section{MATERIALS AND METHODS}

Coir fibres were obtained from Tawaeli - Palu area, Central Sulawesi, Indonesia. Such fibres were extracted from coconut husk by mechanical extraction and then cleaned. Surface treatment of coir fibre in this study used sodium bicarbonate $\left(\mathrm{NaHCO}_{3}\right)$ solution. Fibres were soaked in different densities of sodium bicarbonate solution (8 wt.\%, 10 wt. $\%$ and 12 wt.\%) for 24 hours and 120 hours at room temperature. After soaking, fibres were washed with distillated water and dried in room temperature for 24 hours, then followed by drying in oven at $110^{\circ} \mathrm{C}$ for 1 hour [13] as shown in Figure 1. 

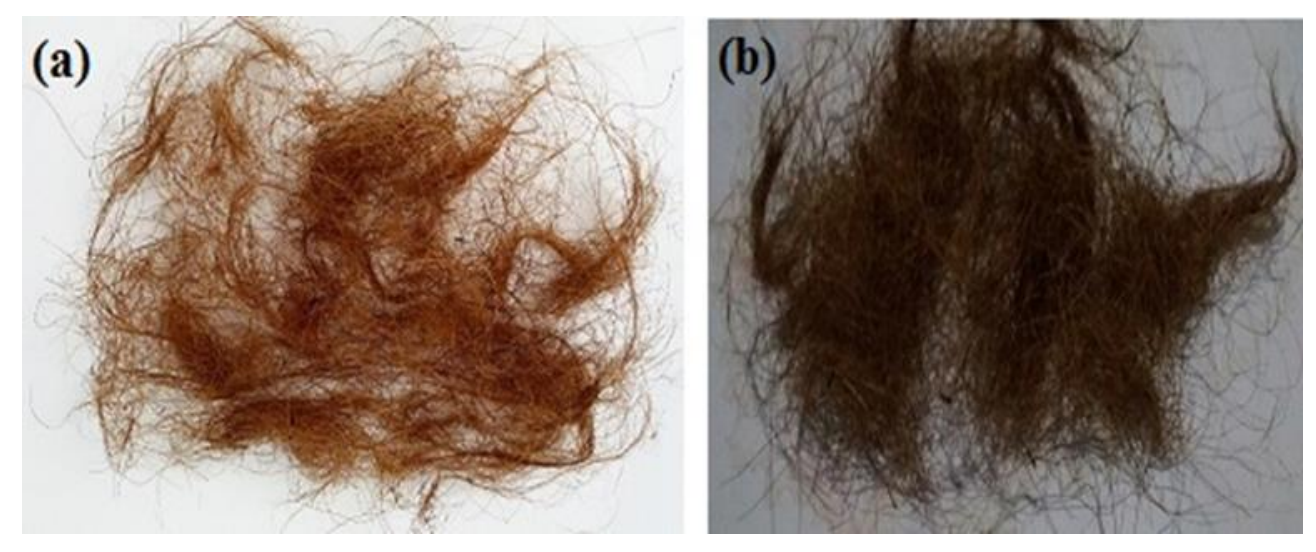

Figure 1. (a) Raw coir fibres and (b) $\mathrm{NaHCO}_{3}$ solution treated coir fibres.

Tensile testing of coir fibre was conducted by using Llyod L10K Plus Universal Testing Machine following procedure provided by ASTM 3379. The gauge length of fibre specimen was $30 \mathrm{~mm}$ and crosshead rate was set at $2.5 \mathrm{~mm} / \mathrm{min}$. To calculate fibre stress, diameter of fibre was measured by optical microscope. Surface morphology of coir fibre was characterized with SEM - JEOL JSM 6510 LA.

FTIR characterisation was conducted with using IRPrestige-21 FTIR-8400S SHIMADZU. A small portion of coir fibre powder was taken for FTIR spectroscopy, ground with $\mathrm{KBr}$ reagent $(\mathrm{KBr}$ : coir fibre powder = 10:1) using mortar and pestle. Then, the mixture was formed into pellet using a dice and hand press machine. Then, the pellet was placed on the sample holder. The IR spectrum was obtained and then analyzed.

An XRD-7000 X-Ray Diffraction SHIMADZU type X-ray powder diffraction was utilized to determine crystallinity index of raw and treated of coir fibres. The $\mathrm{X}$-ray tube is the copper $(\mathrm{Cu})$ type and generates at $40 \mathrm{kV}$ and $30 \mathrm{~mA}$. The diffraction machine was operated at a scan speed of 2 degree/min with sampling pitch of $0.02^{\circ}$. The samples were scanned from the range $2 \theta$, varying from $10^{\circ}$ to $40^{\circ}$ for raw and sodium bicarbonate treated fibres. Index of crystallinity is calculated based on Segal method as in Eq. (1) [25].

$\mathrm{CI}(\%)=\frac{\mathrm{I}_{002}-\mathrm{I}_{\mathrm{am}}}{\mathrm{I}_{002}}$

where $\mathrm{I}_{002}$ is the maximum intensity diffraction of peak and $\mathrm{I}_{\mathrm{am}}$ is the minimum intensity diffraction of peak.

\section{RESULTS AND DISCUSSION}

\section{Mechanical Properties of Raw and Treated Coir Fibre}

Tensile strength and strain of raw and sodium bicarbonate treatment coir fibres are shown in Figure 2 and Figure 3. Sodium bicarbonate solution consist of three densities or compositions: $8 \mathrm{wt} . \%, 10 \mathrm{wt} . \%$ and $12 \mathrm{wt} . \%$ with time differences of soaking of 24 hours and 120 hours. As can be seen in Figure 2, tensile strength of raw coir fibre is $142.39 \mathrm{MPa}$ which is lower than that of $10 \mathrm{wt} . \%$ for 24 hours and $12 \mathrm{wt} . \%$ for 120 hours treatment. This strength is lower than have reported [19]. The highest tensile strength among all is treated coir fibre in $12 \mathrm{wt} . \%$ for 120 hours soaking of sodium 
bicarbonate reaching $167.85 \mathrm{MPa}$. It increased about $17 \%$ from the tensile strength of raw fibre. Such treatment of coir fibres has less micropores or damage in the surface after treatment as can been in Figure 4 and Figure 5. The removal of substances on the surface of coir after alkali treatment contributes to change the tensile strength of coir fibre [20]. Meanwhile, strains or elongations of raw and treated fibres did not significantly change after treatment for 24 and 120 hours. The strain of coir fibre increased between $20 \%$ and $30 \%$.

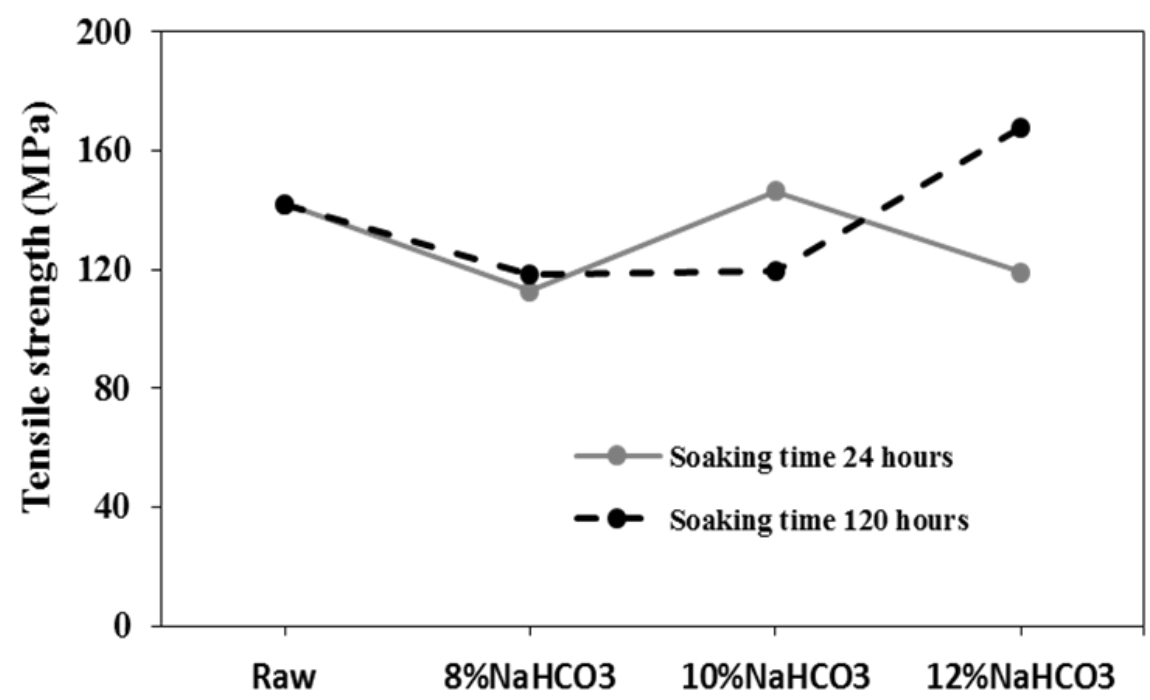

Figure 2. Tensile strength of raw and $\mathrm{NaHCO}_{3}$ solution treatment coir fibres.

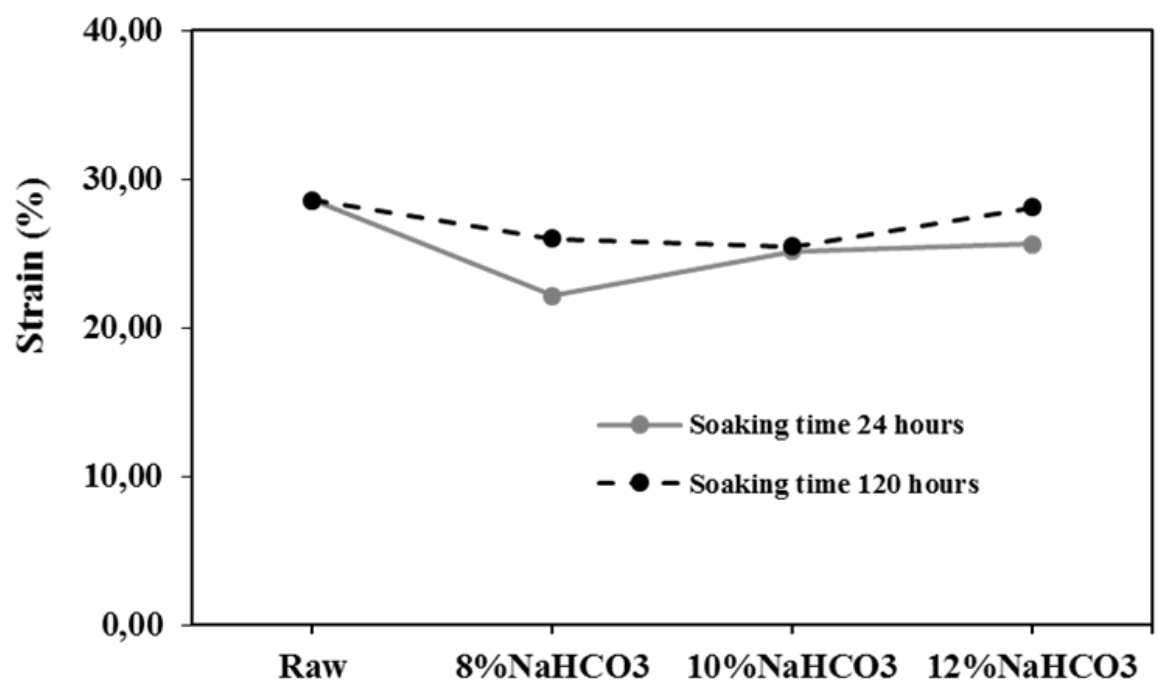

Figure 3. Strain of raw and $\mathrm{NaHCO}_{3}$ solution treatment coir fibres.

\section{Surface Morphology of Coir Fibre}

Figure 4 and Figure 5 show the surface morphology of raw and treated coir fibre images taken from SEM characterisation. As can be seen in Figure 4, raw fibre surface contained some impurities whereas treated fibre surfaces did not have impurities. But, 
the samples with 8 wt.\% and 12 wt. $\% \mathrm{NaHCO}_{3}$ treatment exhibit micropores on their surfaces. This micropores may induce tensile strength of fibres to decrease.

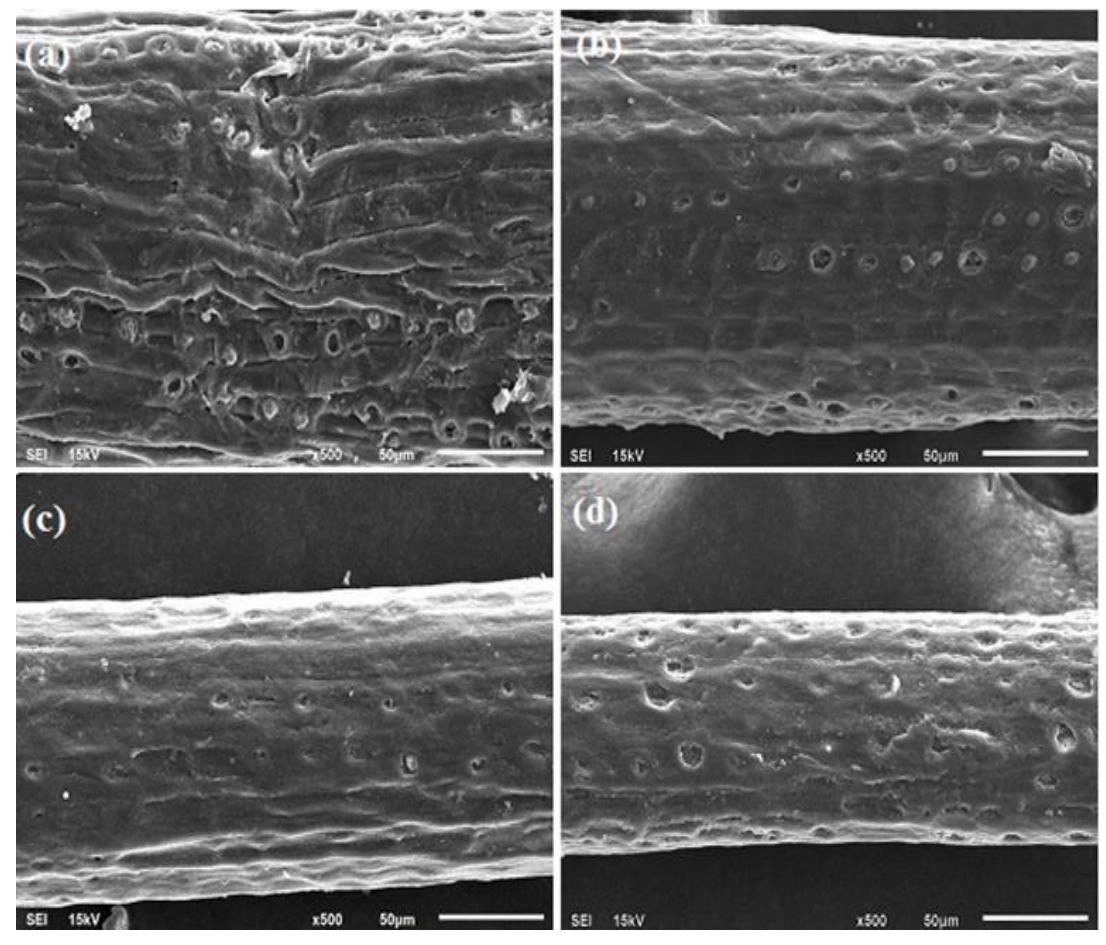

Figure 4. SEM images of (a) raw coir fibre and; solution treated coir fibre at (b) $8 \%$ and; (c) $10 \%$, (d) $12 \% \mathrm{NaHCO}_{3}$ after soaking for 24 hours.

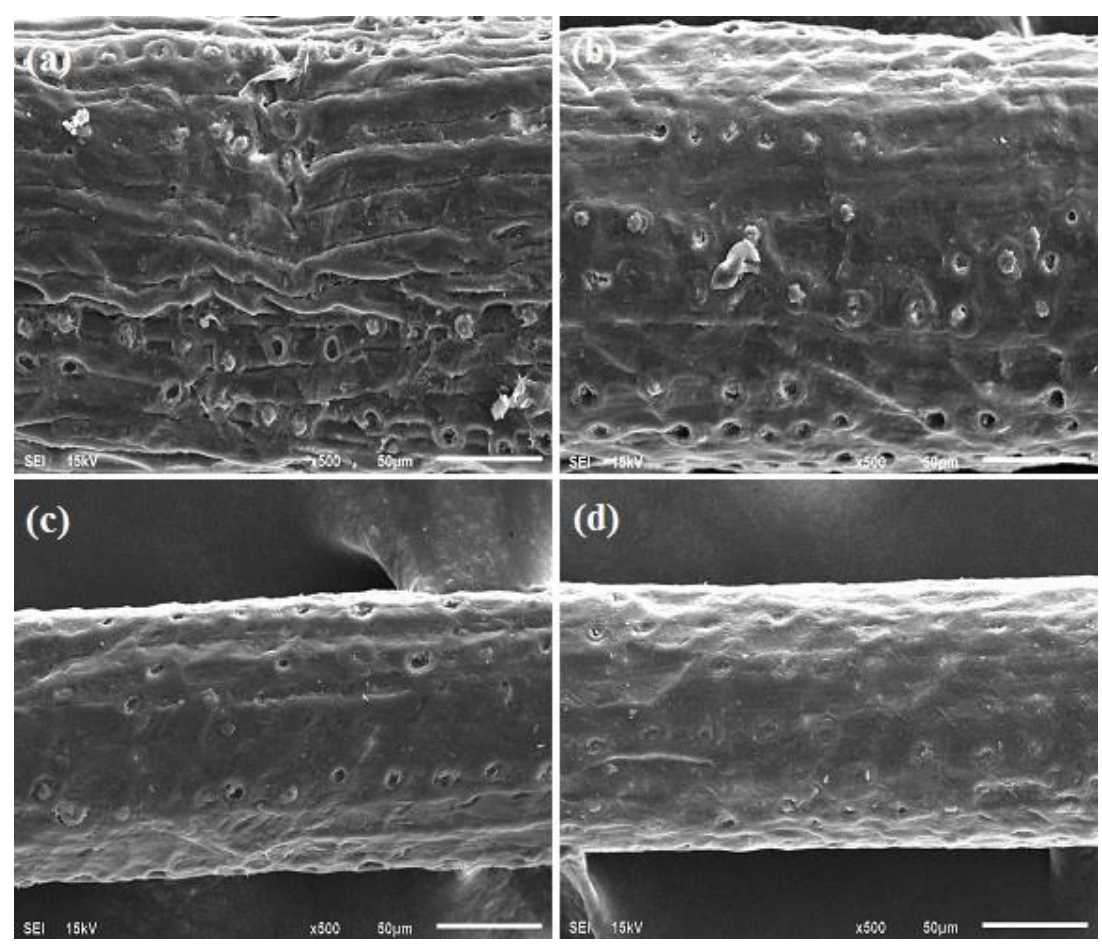

Figure 5. SEM images of (a) raw coir fibre and; solution treated coir fibre at (b) $8 \%$ and; (c) $10 \%$, (d) $12 \% \mathrm{NaHCO}_{3}$ after soaking for 120 hours. 
Similarly, treated fibre for 120 hours soaking in Figure 5, micropores appear in the treatment of 8 wt. $\%$ and 10 wt. $\% \mathrm{NaHCO}_{3}$. Whereas, for $12 \% \mathrm{NaHCO}_{3}$ with 120 hours, only few much micropores existed on its surface relative to other samples. This may explain the tensile strength of 12 wt.\% $\mathrm{NaHCO}_{3}$ with 120 hours soaking time reached the highest level among all treated samples. These results suggested that appropriate density of $\mathrm{NaHCO}_{3}$ and soaking time may enhance the tensile strength of coir fibre. The result also implied the potential characteristic of coir fibre to be used as reinforcement in matrix composite. The micropores, however, can serve as interlocking bonding between matrix and fibre [8].

\section{FTIR Characterisation of Coir Fibre}

FTIR spectrum of raw and sodium bicarbonate treated coir fibres is illustrated in Figure 6. Raw coir fibre spectrum in Figure 6(a) shows OH-stretching vibration of cellulosic structure with peak intensity $3442 \mathrm{~cm}^{-1}$ similar to the result reported by Samal et al. [26]. This peak intensity tends to shift after sodium bicarbonate soaking. Shifting of this peak intensity after treating the coir fibre agree with previous study [17,27]. Intensity position between 3200 to $3600 \mathrm{~cm}^{-1}$ suggested a strong band from cellulose, hemicellulose and lignin of coir fibre [17]. Cellulose, hemicellulose and lignin are the main chemical components of coir fibre. Peaking at $2912 \mathrm{~cm}^{-1}$ band is a characteristic band for $\mathrm{C}-\mathrm{H}$ stretching vibration of cellulose/hemicellulose [26]. The $\mathrm{C}=\mathrm{O}$ linkage of hemicellulose in the raw coir fibre is exhibited by band of $1743 \mathrm{~cm}^{-1}$ which changes after sodium bicarbonate treatment $[26,28]$. Peaking bands at $1602 \mathrm{~cm}^{-1}$ and $1512 \mathrm{~cm}^{-1}$ of raw coir fibre related to $\mathrm{C}=\mathrm{C}$ aromatic stretching vibration due to lignin $[17,26]$. Then, bands at range $1030-1462 \mathrm{~cm}^{-1}$ of raw coir fibre are associated to various possible assignments including $\mathrm{C}-\mathrm{O} / \mathrm{C}-\mathrm{C}$ stretching vibrations, asymmetric in phase ring stretching, asymmetric $\mathrm{C}-\mathrm{O}-\mathrm{C}$ stretching, interaction between $\mathrm{O}-\mathrm{H}$ bending and $\mathrm{C}-\mathrm{O}$ stretching, aliphatic $\mathrm{C}-\mathrm{H}$ bending vibration, $\mathrm{OH}$ in plane bending, and $\mathrm{CH}_{2}$ bending vibration in glucopyranose of cellulose [26].

\section{XRD Characterisation of Coir Fibre}

$\mathrm{X}$-Ray diffraction analysis of raw and sodium bicarbonate treatment of coir fibres is shown in Figure 7 and in Table 1. Crystallinity index (CI) of treated coir fibres tend to increase which exhibits the improvement of restructure of cellulose. It may also improve the tensile strength of fibres [6,12]. The opposite result was found by Mwaikambo and Ansell [29] where CI increased with tensile strength decreased for alkali treatment of sisal fibre. It may occur because the treatment may lead to rupture the primary wall of fibre which influences to the crystalline regions. The $12 \mathrm{wt} \%$ sodium bicarbonate treatment for 24 hours has the highest of crystallinity index (CI) where it rises approximately $14.68 \%$ from raw fibre. However, the crystallinity index of coir fibre in this research is lower than reported before by Satyanarayana et al. [30], Tomczak et al.[18] and Arsyad et al. [11]. 


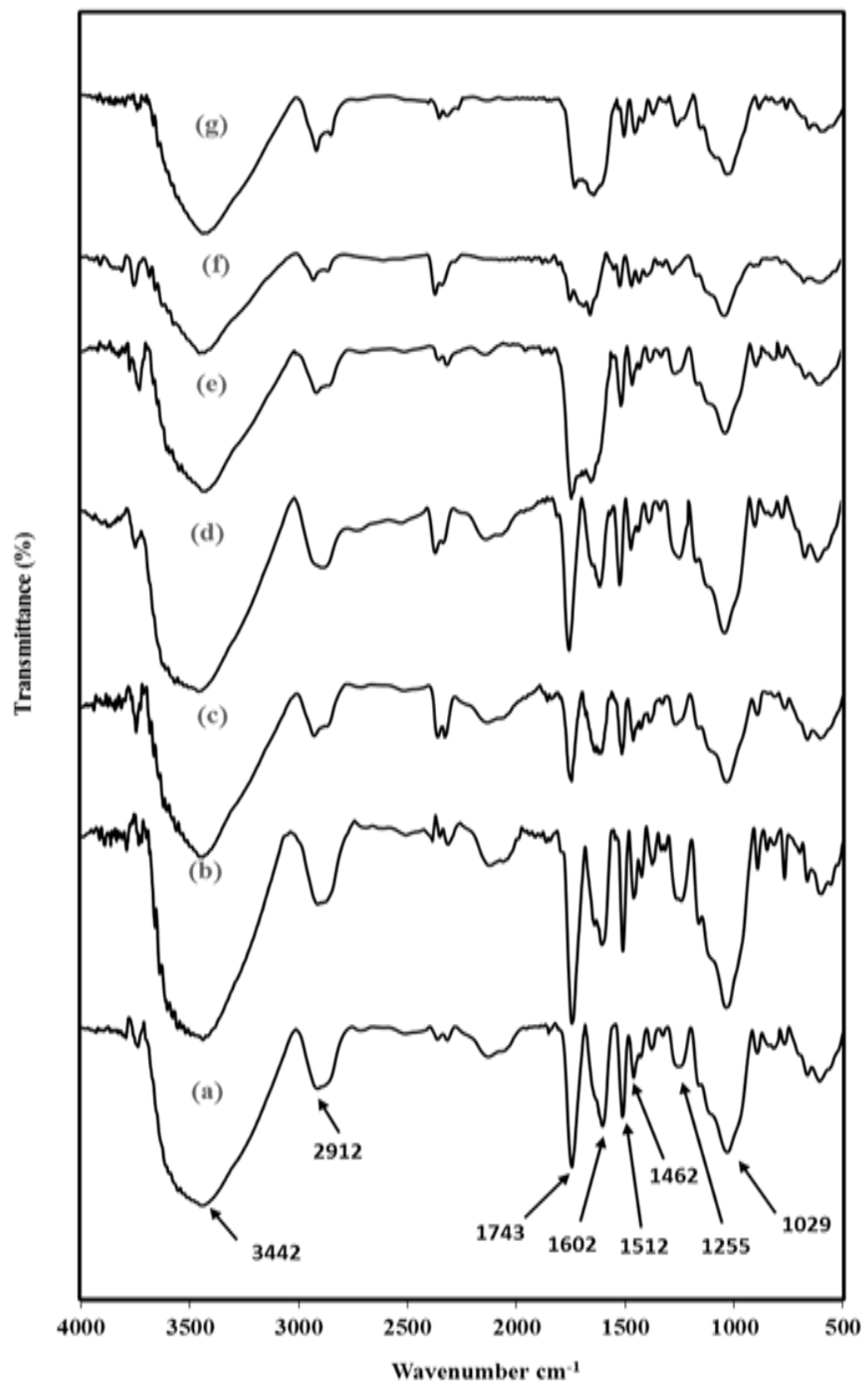

Figure 6. FTIR spectrum of (a) raw coir fibres and; treated coir fibres at (b) $8 \%$,

(c) $10 \%$ and (d) $12 \% \mathrm{NaHCO}_{3}$ for 24 hours and $\mathrm{NaHCO}_{3}$ treated coir fibres at (e) $8 \%$, (f) $10 \%$ and (g) $12 \% \mathrm{NaHCO}_{3}$ for 120 hours. 


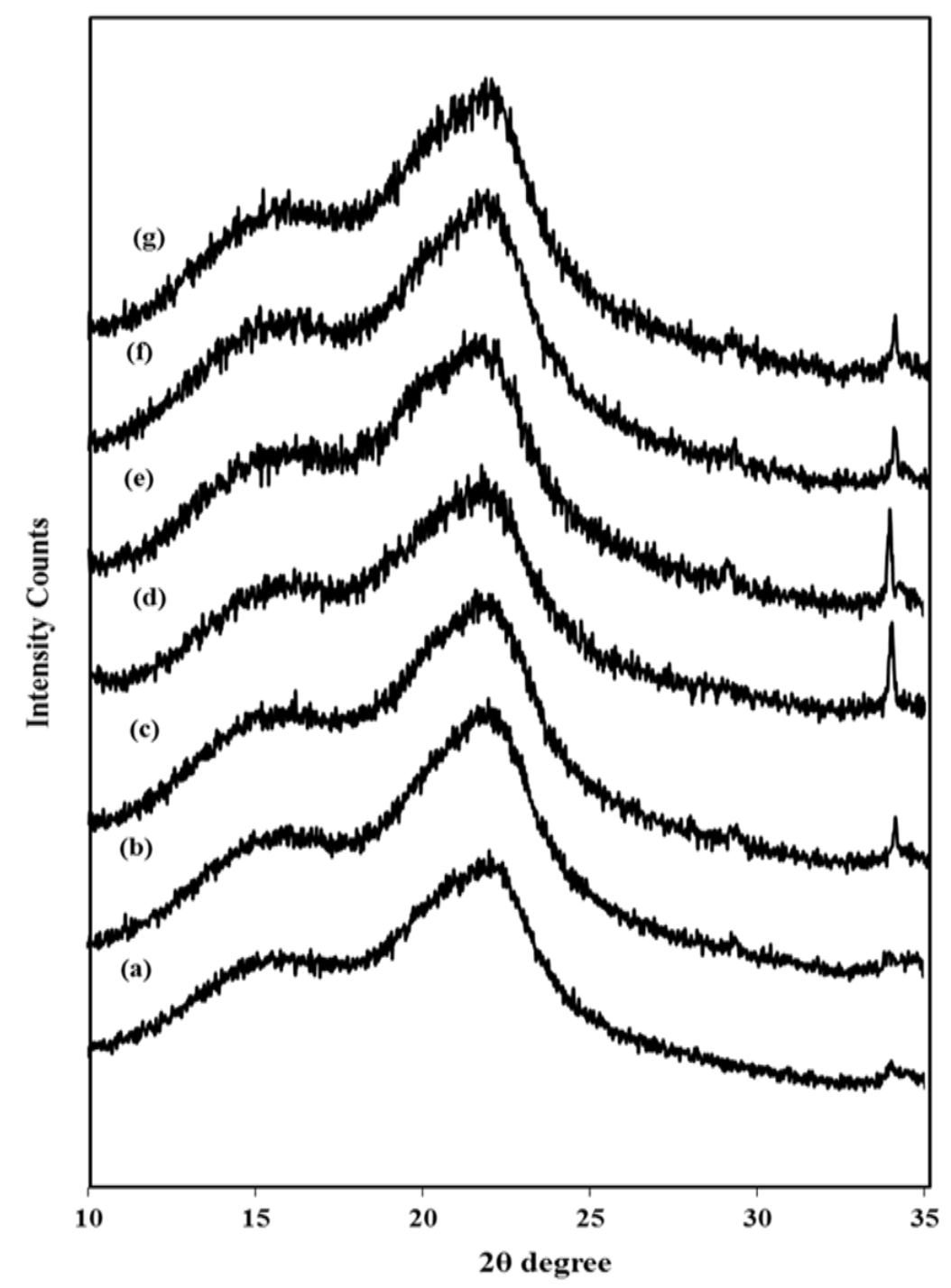

Figure 7. XRD of (a) raw coir fibres and; treated coir fibres at (b) $8 \%$, (c) $10 \%$, (d) $12 \% \mathrm{NaHCO}_{3}$ for 24 hours and treated coir fibres at (e) $8 \%$, (f) $10 \%$, (g) $12 \%$ $\mathrm{NaHCO}_{3}$ for 120 hours.

Table 1. Crystallinity index of coir fibre before and after $\mathrm{NaHCO}_{3}$ treatment.

\begin{tabular}{llccc}
\hline \multirow{2}{*}{ Samples } & & \multicolumn{3}{c}{ Crystallinity index, CI (\%) } \\
\cline { 3 - 5 } & & 35.02 & 24 Hours & 120 Hours \\
\hline Raw & $8 \%$ & 38.50 & 34.92 \\
$\mathrm{NaHCO}_{3}$ & $10 \%$ & 34.25 & 37.38 \\
Treatment & $12 \%$ & 40.16 & 36.29 \\
\hline
\end{tabular}

\section{CONCLUSION}

In this research, coir fibres were treated with 8 wt.\%, 10 wt.\%, and $12 \mathrm{wt} . \%$ sodium bicarbonate $\left(\mathrm{NaHCO}_{3}\right)$ solution for 24 hours and 120 hours. The mechanical and morphological properties of coir fibre were investigated. Tensile strength of coir fibre 
after sodium bicarbonate treatment changed for all densities and soaking time. The sample with 12 wt.\% sodium bicarbonate for 120 hours soaking time exhibited the highest tensile strength relative to other samples. The SEM images revealed micropores existence on its surface morphology after treatment in certain density of sodium bicarbonate. These micropores promote local stress concentration causing tensile strength weakening. However, soaking the coir fibres in $12 \mathrm{wt} . \%$ sodium bicarbonate for 120 hours exhibited only few the micropores. As a result, the tensile strength increased. FTIR and XRD characterisation demonstrated that after sodium bicarbonate treatment of coir fibre, peak intensities are shifted, and crystallinity index tended to increase. Further study is needed by facilitating the micropores as an interlock bonding between fibre and matrix composite.

\section{AKNOWLEDGEMENT}

The authors are thankful to Ministry of Research, Technology and Higher Education for financial grant to support this research work. Also, the authors would like to acknowledge the SEM Laboratory FMIPA-The Bandung Institute of Technology, Research and Science Development Laboratory FMIPA-Hasanuddin University, and Material Laboratory-Academy of Industrial Engineering-Makassar.

\section{REFERENCES}

[1] Rout J, Misra M, Tripathy SS, Nayak SK, Mohanty AK. The influence of fibre treatment on the performance of coir-polyester composites. Composite Science and Technology. 2001; 61(9): 1303-1310.

[2] Joshi SV, Drzal LT, Mohanty AK, Arora S. Are natural fibre composites environmentally superior to glass fibre reinforced composites? Composites Part A: Applied Science and Manufacturing. 2004;35(3):371-376.

[3] Fiore V, Scalici T, Nicoletti F, Vitale G, Prestipino M, Valenza A. A new ecofriendly chemical treatment of natural fibres: Effect of sodium bicarbonate on properties of sisal fibre and its epoxy composites. Composite Part B: Engineering. 2016; 85: 150-160.

[4] Jayavani S, Deka H, Varghese TO, Nayak SK. Recent development and future trends in coir fibre reinforced green polymer composites: Review and Evaluation. Polymer Composite. 2015;1-14.

[5] Herrera-Franco PJ, Valadez-González A. A study of the mechanical properties of short natural-fibre reinforced composites. Composite Part B: Engineering. 2005;36(8):597-608.

[6] Haameem J, Abdul Majid MS, Afendi M, Haslan M, Fahmi I. Alkaline treatment and thermal properties of Napier grass fibres. International Journal of Automotive and Mechanical Engineering. 2016; 13(1): 3238-3247.

[7] Silva GG, Souza DAD, Machado JC, Hourston DJ. Mechanical and thermal characterisation of native Brazilian coir fibre. Journal of Applied Polymer Science. 2000; 76: 1197-1206.

[8] Rahman MM, Khan MA. Surface treatment of coir (Cocos nucifera) fibres and its influence on the fibres' physico-mechanical properties. Composite Science and Technology. 2007; 67(11-12):2369-2376.

[9] Nam TH, Ogihara S, Tung NH, Kobayashi S. Effect of alkali treatment on interfacial and mechanical properties of coir fibre reinforced poly (butylene 
succinate) biodegradable composites. Composite Part B: Engineering, 2011; 42(6): 1648-1656.

[10] Tran LQN, Fuentes CA, Dupont-Gillain C, vanVuure AW, Verpoest I. Understanding the interfacial compatibility and adhesion of natural coir fibre thermoplastic composites. Composite Science and Technology. 2013; 80:23-30.

[11] Arsyad M, Wardana ING, Pratikto, Irawan YS. The morphology of coconut fibre surface under chemical treatment. Revista Matéria. 2015; 20(1): 169 - 177.

[12] Reddy KO, Maheswari CU, Shukla M, Song JI, Rajulu AV. Tensile and structural characterisation of alkali treated Borassus fruit fine fibres. Composite Part B: Engineering. 2013;44(1):433-438.

[13] Sures Kumar SM, Duraibabu D, Subramanian K. Studies on mechanical, thermal and dynamic mechanical properties of untreated (raw) and treated coconut sheath fibre reinforced epoxy composites. Material and Design. 2014; 59: 63-69.

[14] Mwaikambo LY, Ansell MP. Chemical modification of hemp, sisal, jute, and kapok fibres by alkalization. Journal of Applied Polymer Science. 2002; 84(12): 2222-2234.

[15] Mohanty AK, Misra M, Drzal LT. Surface modifications of natural fibres and performance of the resulting biocomposites: An overview. Composite Interfaces. 2001;8(5):313-343.

[16] Hossain SI, Hasan M, Hasan MN, Hassan A. Effect of chemical treatment on physical, mechanical and thermal properties of Ladies Finger natural fibre. Advances in Materials Science and Engineering. 2013; 2013:1-6.

[17] Mir SS, Hasan SMN, Hossain MJ, Hasan M. Chemical modification effect on the mechanical properties of coir fibre. Engineering Journal. 2012;16(2):73-83.

[18] Tomczak F, Sydenstricker THD, Satyanarayana KG. Studies on lignocellulosic fibres of Brazil. Part II. Morphology and properties of Brazilian coconut fibres. Composites Part A: Applied Science and Manufacturing. 2007; 38:1710-1721.

[19] Bakri B, Eichhorn SJ. Elastic coils: deformation micromechanics of coir and celery fibres. Cellulose. 2010; 17:1-11.

[20] Prasad SV, Pavithran C, Rohatgi PK. Alkali treatment for coir fibres for coirpolyester composites. Journal of Materials Science. 1983;18(5):1443-1454.

[21] $\mathrm{Gu} \mathrm{H}$. Tensile behaviours of the coir fibre and related composites after $\mathrm{NaOH}$ treatment. Materials and Design. 2009; 30:3931-3934.

[22] Staffa LH, Agnelli JAM, de Souza ML, Bettini SHP. Evaluation of interactions between compatibilizers and photostabilizers in coir fibre reinforced polypropylene composites. Polymer Engineering \& Science. 2017:1-7.

[23] Praveen KM, Thomas S, Grohens Y, Mozetic M, Junkar I, Primc G, Gorjanc M. Investigations of plasma induced effects on the surface properties of lignocellulosic natural coir fibres. Applied Surface Science. 2016; 368:146-156.

[24] de Farias JGG, Cavalcante RC, Canabarro BR, Viana HM, Scholz S, Simão RA. Surface lignin removal on coir fibres by plasma treatment for improved adhesion in thermoplastic starch composites. Carbohydrate Polymers. 2017; 165:429-436.

[25] Chandrasekar M, Ishak MR, Sapuan SM, Leman Z, Jawaid M. A review on the characterisation of natural fibres and their composites after alkali treatment and water absorption. Plastics, Rubber and Composites. 2017; 46(3): 119-136.

[26] Samal RK, Panda BB, Rout SK, Mohanty M. Effect of chemical modification on FTIR spectra. I. Physical and chemical behavior of coir. Journal of Applied Polymer Science. 1995; 58(4): 745-752. 
[27] Haque M, Islam N, Huque M, Hasan M, Islam S, Islam S. Coir fibre reinforced polypropylene composites: Physical and Mechanical Properties. Advanced Composite Materials. 2010;19(1):91-106.

[28] Abraham E, Deepa B, Pothen LA, Cintil J, Thomas S, John MJ, Anandjiwala R, Narine SS. Environmental friendly method for the extraction of coir fibre and isolation of nanofibre. Carbohydrate Polymers. 2013; 92(2): 1477-1483.

[29] Mwaikambo LY, Ansell MP. Mechanical properties of alkali treated plant fibres and their potential as reinforcement materials II. Sisal fibres. Journal of Materials Science. 2006; 41(8): 2497-2508.

[30] Satyanarayana KG, Guimarães JL, Wypych F. Studies on lignocellulosic fibres of Brazil. Part I: Source, production, morphology, properties and applications. Composites Part A: Applied Science and Manufacturing. 2007; 38(7): 16941709. 